\title{
Seeking graphic medicine narratives
}

\author{
Cite as: CMAJ 2018 March 26;190:E368-9. doi: 10.1503/cmaj.171318
}

CMAJ Podcasts: author reading at https://soundcloud.com/cmajpodcasts/171318-enc

MAJ will soon begin publishing graphic medicine articles in its Humanities section. Graphic medicine is a form of visual storytelling that explores narratives of the body, health care, healing and disability. This burgeoning area of medical humanities is part of growing popular interest in graphic storytelling generally. Over the past several decades, artists have expanded the "comics" genre to include themes once thought of as belonging solely to the arena of literature. Graphic medicine explores the emotional and moral dimensions of experience. Scientific medicine determines which facts, disease concepts or medical treatments are right or wrong. Graphic medicine, on the other hand, shows how patients and caregivers are complex and human. Inside these narratives, the reader is given the opportunity to reflect on how personal identity, power and authority, subjectivity, politics, culture and society affect the practice of medicine.

Graphic medicine can challenge the conventional appearance of medicine by exploring what it feels like to do work in which life and death are at stake, or how it feels to live inside a compromised body. More often than not, the genre will push back against authoritative, official or sanitized written medical literature, exploring instead the subjective experience and emotional aspect of being a caregiver or patient.
In the spring of 2017, I attended an event at which my spouse won a Professional Association of Residents of Ontario award for his work as a physician and teacher of internal medicine. As an outsider to the medical profession, I was struck by how doctors spoke openly with each other about their experience of human connection, triumph and the feelings of medicine field were relaying vulnerable, complex and honest stories - but publicly. Tearing down the boundaries of professional decorum, privacy and authority - factors that often prevent reciprocity between cared-for and caregiver - is what graphic medicine can do. Authors like Ian Williams (The Bad Doctor), Georgia Webber (Dumb), Sarah Leavitt

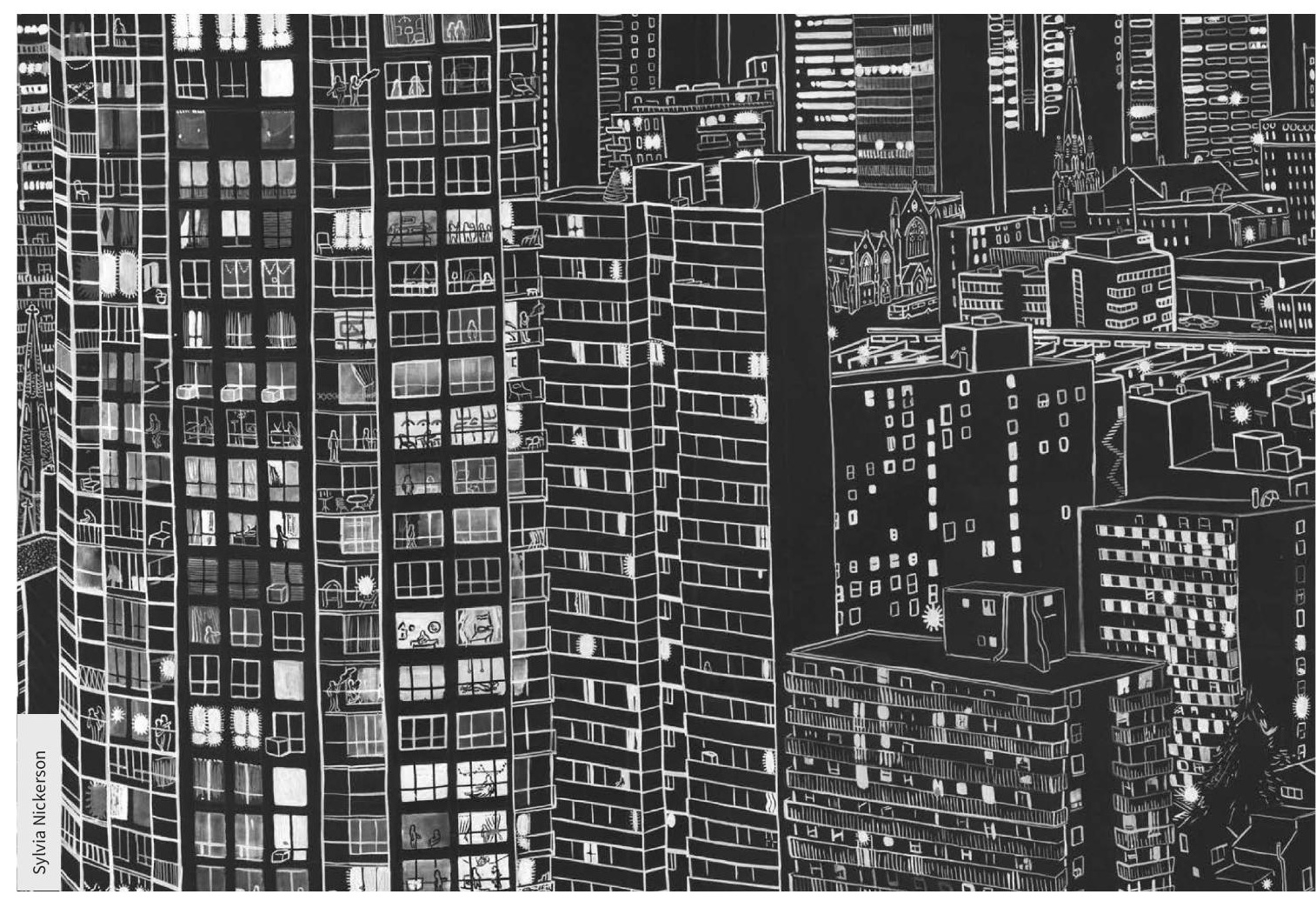

Sylvia Nickerson's illustration of Hamilton's skyline at night appears in her graphic novel, Creation. horror and honour at bearing witness to the most troubling experiences within life's spectrum of extremes. Often, this candour and vulnerability are hidden behind the professional detachment required of health care providers in their caregiving role.

The day after this physician award ceremony, I attended the Toronto Comic Arts Festival. There, artists in the graphic
(Tangles), Teva Harrison (In Between Days) and Jillian Horton \& GMB Chomichuk (Medicine) offer narratives that confound expectation of patient and doctor. These books speak to the experiences of health care professional and client or patient; the experiences people often prefer not to speak openly about because they are uncomfortable. Seeking human connection, graphic medicine helps doctors and 
patients break out of their roles to confront these uncomfortable topics.

In 2016, I admitted to myself that I had an uncomfortable topic to discuss, and began writing a graphic novel about it. The year after my son was born, I was aware I was transforming; my identity was shifting as I became responsible for another human life. During my year of maternity leave, I wandered around my hardscrabble urban neighbourhood, thinking about who I was and why everything I had cared about before having a child seemed so insignificant. Endless walks with my son meant I started to observe life as lived by the poor and homeless in my city. The senseless crime and violence affecting many who live on the street felt tragic and sad. During the idle time I spent nursing, I reflected on how my own sense of self had changed after a difficult childbirth. Not knowing how to overcome the isolation, I began writing down how I felt. My graphic novel addresses poverty, postpartum depression, crime and violence topics not often discussed but that are nevertheless realities of human experience.

When the meaning of life falls out of view, when suffering and incomprehensible things occur, the human response is to make meaning from these events, to try and recover balance, normalcy and an explanatory framework within which one can feel at peace. Graphic medicine and comic storytelling can help readers make sense of their experience. For those with these questions, this new addition to the Humanities section could expand their perspective. Watch this space.

\section{Sylvia M. Nickerson BFA PhD}

Hamilton, Ont.

This article was solicited and has been peer reviewed. 